\title{
Synthesis and Corrosion Resistance of ZnAl Layered Double Hydroxide Film on Q235 Steel
}

\author{
Shuyu Xie ${ }^{1,2}$, Jihui Wang ${ }^{1,2, *}$, Wenbin $\mathrm{Hu}^{2}$ \\ ${ }^{1}$ State Key Laboratory of Hydraulic Engineering Simulation and Safety, Tianjin University, Tianjin \\ 300072, P R China \\ ${ }^{2}$ Tianjin Key Laboratory of Composite and Functional Materials, School of Materials Science and \\ Engineering, Tianjin University, Tianjin 300072, P R China \\ *E-mail: jhwang@tju.edu.cn
}

doi: $10.20964 / 2019.07 .29$

Received: 8 March 2019 / Accepted: 29 April 2019 / Published: 10 June 2019

\begin{abstract}
$\mathrm{ZnAl}-\mathrm{MoO}_{4}-\mathrm{LDH}$ film was fabricated in situ on the Q235 steel substrate by aluminizing process, coprecipitation method and ion-exchange method. The morphology, composition and structure of the LDHs film were analyzed by scanning electron microscopy (SEM), X-ray diffraction (XRD) and Fourier transform infrared (FT-IR) spectroscopy. The anticorrosion capability of the Q235 steel with LDHs film was observed by electrochemical impedance spectroscopy (EIS) and polarization curve. The LDHs film had a plate-like morphology which is the typical grain morphology of LDHs, and a particle size ranging from $2 \mu \mathrm{m}$ to $4 \mu \mathrm{m}$ and a particle thickness ranging from $0.05 \mu \mathrm{m}$ to $0.2 \mu \mathrm{m}$. The increase of the layer spacing of LDHs film and the absorption peak of $\mathrm{MoO}_{4}{ }^{2-}$ in FT-IR spectra can prove the intercalation of $\mathrm{MoO}_{4}{ }^{2-}$. Compared with bare Q235 steel, the corrosion current density of the Q235 steel with LDHs film decreased and the polarization resistance increased. The improvement of corrosion resistance is owed to the LDHs film which plays as a barrier between the substrate and the corrosive medium. The exchangeability of the interlayered anions of LDHs can catch the corrosive chloride ion in the medium and the $\mathrm{MoO}_{4}{ }^{2-}$ released from the LDHs layer can play as corrosion inhibitor.
\end{abstract}

Keywords: layered double hydroxide film; corrosion protection; in-situ growth; carbon steel

\section{$\underline{\text { FULL TEXT }}$}

(C) 2019 The Authors. Published by ESG (www.electrochemsci.org). This article is an open access article distributed under the terms and conditions of the Creative Commons Attribution license (http://creativecommons.org/licenses/by/4.0/). 